\title{
Optimized and coordinated model predictive control scheme for DFIGs with DC-based converter system
}

\author{
Shaomin YAN ${ }^{1,3}$, Aimin ZHANG $^{2}$, Hang ZHANG ${ }^{1}$, Jianhua WANG ${ }^{1}$, \\ Bin $\mathrm{CAI}^{3}$
}

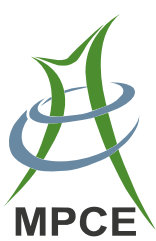

\begin{abstract}
This paper proposes an optimized and coordinated model predictive control (MPC) scheme for doublyfed induction generators (DFIGs) with DC-based converter system to improve the efficiency and dynamic performance in DC grids. In this configuration, the stator and rotor of the DFIG are connected to the DC bus via voltage source converters, namely, a rotor side converter (RSC) and a stator side converter (SSC). Optimized trajectories for rotor flux and stator current are proposed to minimize Joule losses of the DFIG, which is particularly advantageous at low and moderate torque. The coordinated MPC scheme is applied to overcome the weaknesses of the field-oriented control technique in the rotor flux-oriented frame, which makes the rotor flux stable and the stator current track its
\end{abstract}

CrossCheck date: 1 June 2017

Received: 23 February 2017/Accepted: 12 June 2017/Published online: 17 July 2017

(C) The Author(s) 2017. This article is an open access publication

$\triangle$ Aimin ZHANG

zhangam@mail.xjtu.edu.cn

Shaomin YAN

qfnuyan@163.com

Hang ZHANG

zhangh@mail.xjtu.edu.cn

Jianhua WANG

jhwang@mail.xjtu.edu.cn

Bin CAI

bincai1027@126.com

1 School of Electrical Engineering, Xi' an Jiaotong University, Xi' an, China

2 School of Electronic and Information Engineering, Xi' an Jiaotong University, Xi'an, China

3 School of Engineering, Qufu Normal University, Rizhao, China reference closely and quickly. Lastly, simulations and experiments are carried out to validate the feasibility of the control scheme and to analyze the steady-state and dynamic performance of the DFIG.

Keywords Coordinated model predictive control (MPC) scheme, Doubly-fed induction generator (DFIG),

DC-based converter system, Optimized trajectories, Rotor side converter (RSC), Stator side converter (SSC)

\section{Introduction}

Wind energy generation has attracted great interest due to its freely available, clean and renewable resource. The adoption of doubly-fed induction generators (DFIGs) for wind turbines has allowed the power rating of wind turbines to increase in AC grid [1]. The traditional DFIG converter system has many merits, such as small power capacity, low energy losses and cost, flexible power control [2-4]. However, it cannot easily satisfy the requirements of high-voltage direct-current (HVDC) transmission systems based on voltage-source conversion (VSC). Extra rectifiers are applied to connect the stator and traditional DIFG converter system with a DC bus, so that the cost increases due to this redundant structure [5].

Therefore, a DC-based converter system has been proposed to interface a DFIG with a DC grid. A diode-based converter interfaces the stator with the DC grid to simplify its structure and reduce its cost. A power control scheme for a DFIG is proposed with a diode-based rectifier connected to the DC Bus [6]. The stator frequency is regulated by an inner control method [7]. Torque ripple is reduced by resonant current controllers [8]. Operation and design issues are analyzed for a DFIG with a diode-based rectifier [9]. Self-sensing methods for regulating stator 
current and stator frequency are proposed for DFIG $[10,11]$. But harmonics caused by diode-based rectifiers may reach from $5.97 \%$ to $11.66 \%$ and an active power filter should be applied to eliminate these $[12,13]$. The IGBTbased DFIG converter system adopted in this paper, which consists of a rotor side converter (RSC) and a stator side converter (SSC), regulates DFIG more flexibly, with reduced harmonics $[14,15]$.

A DC-based converter system make it possible to regulate flux and current in the DFIG to minimize system loss and adapt it to various applications, because the SSC connects the stator to the DC grid and the stator is not confined to the AC grid. A SSC regulates its frequency and voltage to make the DFIG operate at low wind speed with fixed slip [14]. However system dissipation cannot be ignored, particularly at low and moderate torques.

Optimization strategies for DFIGs in AC and DC grids have been investigated as follows. Optimization of a DFIG in the AC grid only deals with the sharing of exciting current, while additional reactive power devices are needed to compensate reactive power [16]. The field weakening method is used to extend the rotor speed range of induction, and suitable flux and current trajectories are found to reduce system losses [17, 18]. The field weakening method is applied to a DFIG with a diode-based converter to improve its efficiency in a DC grid [19]. However, its efficiency only increases by $12 \%$ while the stator frequency increases by $200 \%$ at low torque and rotor speed. The higher stator frequency leads to more design difficulty and increases the cost of the diode-based converter. Optimization strategies for a DFIG with an IGBT-based converter system connecting to a DC grid are hardly mentioned in the literature, especially at the low speed and torque.

Field-oriented control techniques consisting of inner and outer loops are usually used to control DFIG power due to their simplicity [20,21]. But it is difficult to choose suitable control parameters to ensure system stability under different conditions. Alternative control strategies have been proposed to overcome these drawbacks [22, 23]. Model predictive control (MPC) is an attractive solution for current, power, torque and flux control due to its easy design, fast dynamic response, high accuracy and small steady-state error under different conditions [24]. Compared with a PI controller, a MPC controller obtains faster responses and has less overshoot [25, 26]. MPC has been applied to DFIGs not only in the AC grid, but also in the DC grid [27-30]. However, MPC for a DFIG with two IGBT-based converters, to improve the dynamic and steady-state performance of the DFIG in the DC grid, is also hardly mentioned in the literature.

Considering the problems mentioned above, this study focuses on the optimization strategy to improve the efficiency of a DFIG with IGBT-based converters connected to a DC grid, which is the main contribution of this paper. Unlike previous optimization strategies for DFIGs, an optimization method for rotor flux and stator current is proposed to minimize system losses. The optimal values are analytically obtained and validated on a detailed model.

Furthermore, a coordinated MPC scheme for the RSC and the SSC is presented to overcome the drawbacks of the field-oriented control technique and improve the steadystate and dynamic performance of the DFIG. A stator current and rotor flux predictive method is used in the MPC controllers. Finally, experimental and simulation studies are carried out to validate the effectiveness.

\section{System description}

\subsection{DC-based converter system}

The DC-based converter system adopted in this paper is shown in Fig. 1.

The stator and rotor of DFIG are connected to the DC bus by the SSC and RSC. The stator voltage is not enslaved to the AC grid any more, and the SSC can regulate the stator voltage and frequency flexibly to control the stator current and compensate the stator reactive power. In addition, the RSC can regulate the rotor voltage flexibly to control the rotor flux.

\subsection{Wind turbine model description}

In this paper, the models of the gearbox and the wind turbine are merged into one part. And its maximum power point (MPP) curve assumed in this paper is approximatively given by [31]

$\left\{\begin{array}{c}T_{\text {opt }}=0.0667 V_{w}^{2} \\ n_{\text {ropt }}=111.8 V_{w}\end{array}\right.$

where $T_{\text {opt }}(\mathrm{N} \cdot \mathrm{m}), n_{\text {ropt }}(\mathrm{krpm})$, and $V_{w}(\mathrm{~m} / \mathrm{s})$ are the optimum mechanical torque, optimum rotor speed, and wind speed respectively.

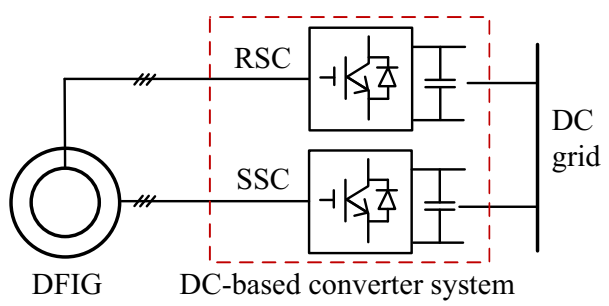

Fig. 1 DFIG with its DC-based converter system in DC grid 


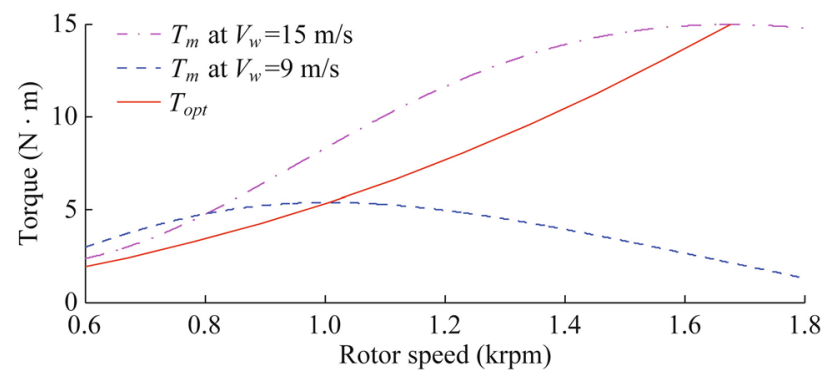

Fig. 2 Variation of wind turbine performance with rotor speed

Wind turbine performance curves are shown in Fig. 2, as the rotor speed $\left(n_{r}\right)$ ranges from 0.6 to $1.7 \mathrm{krpm}$. The solid line is for the curve of optimum mechanical torque. The other lines are the curves of mechanical torque $\left(T_{m}\right)$ at the wind speeds of 9 and $15 \mathrm{~m} / \mathrm{s}$ respectively.

\subsection{DFIG model description}

The dynamic DFIG model in the $d q$ synchronous frame can be expressed as $[20,21]$

$$
\begin{aligned}
& \left\{\begin{array}{l}
u_{s d}=\frac{\mathrm{d} \psi_{s d}}{\mathrm{~d} t}-\omega_{1} \psi_{s q}+R_{s} i_{s d} \\
u_{s q}=\frac{\mathrm{d} \psi_{s q}}{\mathrm{~d} t}+\omega_{1} \psi_{s d}+R_{s} i_{s q} \\
u_{r d}=\frac{\mathrm{d} \psi_{r d}}{\mathrm{~d} t}-\omega_{s} \psi_{r q}+R_{r} i_{r d} \\
u_{r q}=\frac{\mathrm{d} \psi_{r q}}{\mathrm{~d} t}+\omega_{s} \psi_{r d}+R_{r} i_{r q}
\end{array}\right. \\
& \left\{\begin{array}{l}
\psi_{s d}=L_{s} i_{s d}+L_{m} i_{r d} \\
\psi_{s q}=L_{s} i_{s q}+L_{m} i_{r q} \\
\psi_{r d}=L_{r} i_{r d}+L_{m} i_{s d} \\
\psi_{r q}=L_{r} i_{r q}+L_{m} i_{s q}
\end{array}\right. \\
& \left\{\begin{array}{c}
T_{m}-T_{e}=J \frac{\mathrm{d} \omega_{m}}{\mathrm{~d} t}=\frac{2 \pi J}{60} \frac{\mathrm{d} n_{r}}{\mathrm{~d} t} \\
T_{e}=1.5 n_{p} \frac{L_{m}}{L_{r}}\left(\psi_{r d} i_{s q}-\psi_{r q} i_{s d}\right)
\end{array}\right.
\end{aligned}
$$

where $u_{s d}, u_{s q}, i_{s d}, i_{s q}, \psi_{s d}$, and $\psi_{s q}$ are the $d q$ components of stator voltage, current and flux respectively; $u_{r d}, u_{r q}, i_{r d}$, $i_{r q}, \psi_{r d}$, and $\psi_{r q}$ are the $d q$ components of rotor voltage, current and flux respectively; $\omega_{1}, \omega_{s}$, and $\omega_{m}$ are synchronous, slip, and mechanical angular frequency respectively; $L_{s}, L_{r}$, and $L_{m}$ are the stator, rotor and mutual inductance respectively; $R_{r}$ and $R_{s}$ are the rotor and stator resistance respectively; $T_{e}$ is electromagnetic torque; $J$ is generator rotational inertia; and $n_{p}$ is the number of pairs of poles.

\section{Control strategy description}

\subsection{MPP control strategy}

Rotor speed $n_{r}$, here approximated by (1), is usually regarded as the tracked target to make the DFIG operate at its MPP. The MPP controller is given by (5), and its output is $T_{e}$ subject to a range limitation from $T_{\min }$ to $T_{\max }$ :

$$
T_{e}=T_{\text {opt }}-k_{p}\left(n_{\text {ropt }}-n_{r}\right)
$$

The dynamic responses of $n_{r}$ and $T_{e}$ increase in proportion to the rotor speed error with coefficient $\left(k_{p}\right)$. The risk of mechanical faults increases with the variation speed of mechanical stress. Here $k_{p}$ is chosen as 0.0628 .

\subsection{Optimized control targets for DFIG}

The rotor flux and the stator current are the control targets, which are optimized in this paper. Within the limitation of rated stator voltage, the proposed optimization method minimizes system losses. The maximum rotor flux is determined by rated stator voltage, because stator overvoltage causes danger and increases the design difficulty of the SSC.

From (3), when a rotor-oriented flux frame is adopted with its vector direction aligned with the $q$-axis, the rotor flux $\left(\psi_{r}\right)$ and its $d q$ components are given by

$\left\{\begin{array}{l}\psi_{r d}=0 \\ \psi_{r q}=\psi_{r}\end{array}\right.$

The rotor currents are accordingly derived from (3):

$\left\{\begin{array}{l}i_{r d}=-\frac{L_{m} i_{s d}}{L_{r}} \\ i_{r q}=\frac{\psi_{r}-L_{m} i_{s q}}{L_{r}}\end{array}\right.$

Substituting (7) into (3), the stator fluxes are obtained:

$\left\{\begin{array}{l}\psi_{s d}=\left(L_{s}-\frac{L_{m}^{2}}{L_{r}}\right) i_{s d} \\ \psi_{s q}=\frac{L_{m}}{L_{r}} \psi_{r}+\left(L_{s}-\frac{L_{m}^{2}}{L_{r}}\right) i_{s q}\end{array}\right.$

Substituting (6) into (4), the stator active current is given by

$i_{s d}=\frac{T_{e} L_{r}}{-1.5 n_{p} L_{m} \psi_{r}}$

Ignoring both electromagnetic transient processes and the voltage drop due to the stator resistance, the stator voltage $\left(u_{s}\right)$ and its $d q$ components are obtained from (2): 
$\left\{\begin{array}{l}u_{s d}=-\omega_{1} \psi_{s q} \\ u_{s q}=\omega_{1} \psi_{s d}\end{array}\right.$

$u_{s}=\sqrt{u_{s d}^{2}+u_{s q}^{2}}=\omega_{1} \sqrt{\psi_{s q}^{2}+\psi_{s d}^{2}}$

It is well known that the rotor and stator resistances are approximately identical, and the rotor leakage reactance $\left(L_{l r}\right)$ is far less than the mutual inductance $\left(L_{m}\right)$ [32], namely,

$\left\{\begin{array}{l}R_{S} \approx R_{r} \\ L_{r} \approx L_{m}\end{array}\right.$

From (8), (11), and (12), the rotor flux is approximately expressed as

$\psi_{r} \approx \frac{u_{s}}{\omega_{1}} \leq \psi_{r}^{*} \approx \frac{V_{s}}{\omega_{1}}$

where $V_{s}$ and $\psi_{r}^{*}$ are the rated stator voltage and rotor flux respectively.

With iron losses neglected, the total Joule losses $\left(P_{l}\right)$ are given by

$P_{l}=i_{r}^{2} R_{r}+i_{s}^{2} R_{s}=\frac{\left(i_{r d}^{2}+i_{r q}^{2}\right) R_{r}+\left(i_{s d}^{2}+i_{s q}^{2}\right) R_{s}}{2}$

where $i_{r}$ and $i_{s}$ are the effective values of the rotor and stator current.

Substituting (7) and (9) into (14), if the DFIG operates at its MPP, the system losses are expressed as

$$
\begin{aligned}
P_{l}= & 0.5\left(R_{s}+R_{r} \frac{L_{m}^{2}}{L_{r}^{2}}\right)\left(\frac{T_{o p t} L_{r}}{-1.5 n_{p} L_{m} \psi_{r}}\right)^{2} \\
& +0.5\left[i_{s q}^{2}\left(R_{s}+R_{r} \frac{L_{m}^{2}}{L_{r}^{2}}\right)-2 \frac{\psi_{r} L_{m} R_{r}}{L_{r}^{2}} i_{s q}+\frac{R_{r} \psi_{r}^{2}}{L_{r}^{2}}\right]
\end{aligned}
$$

From (12) and (15), it follows that

$P_{l}=R_{s}\left[\left(\frac{T_{o p t}}{1.5 n_{p} \psi_{r}}-\frac{\psi_{r}}{2 L_{r}}\right)^{2}+\left(i_{s q}-\frac{\psi_{r}}{2 L_{r}}\right)^{2}+\frac{T_{o p t}}{1.5 n_{p} L_{r}}\right]$

We define a variable flux $\left(\psi_{t}\right)$ that varies with $T_{o p t}$ according to

$\psi_{t}=\sqrt{\frac{2 L_{r} T_{o p t}}{1.5 n_{p}}}$

The system losses $\left(P_{f c}\right)$ resulting from the rotor flux and stator current optimization method are given by

$P_{f c}= \begin{cases}\frac{R_{s} T_{o p t}}{1.5 n_{p} L_{r}} & \psi_{t} \leq \psi_{r}^{*} \\ R_{s}\left(\frac{T_{o p t}}{1.5 n_{p} \psi_{r}^{*}}-\frac{\psi_{r}^{*}}{2 L_{r}}\right)^{2}+\frac{R_{s} T_{o p t}}{1.5 n_{p} L_{r}} & \psi_{r}^{*}<\psi_{t}\end{cases}$

with $\psi_{r}= \begin{cases}\psi_{t} & \psi_{t} \leq \psi_{r}^{*} \\ \psi_{t}^{*} & \psi_{t}>\psi_{r}^{*}\end{cases}$

$i_{s q}= \begin{cases}\frac{\psi_{t}}{2 L_{r}} & \psi_{t} \leq \psi_{r}^{*} \\ \frac{\psi_{r}^{*}}{2 L_{r}} & \psi_{t}>\psi_{r}^{*}\end{cases}$

$i_{s d}= \begin{cases}-\sqrt{\frac{T_{o p t}}{3 n_{p} L_{r}}} & \psi_{t} \leq \psi_{r}^{*} \\ -\frac{T_{o p t}}{1.5 n_{p} \psi_{r}^{*}} & \psi_{r}^{*}<\psi_{t}\end{cases}$

If DFIG operates in a non-optimization mode, the rotor flux and stator reactive current are equal to the rated value and zero respectively. In this case, the system losses $\left(P_{u}\right)$ are given by

$P_{u}=R_{s}\left(\frac{T_{o p t}}{1.5 n_{p} \psi_{r}^{*}}-\frac{\psi_{r}^{*}}{2 L_{r}}\right)^{2}+R_{s}\left(\frac{\psi_{r}^{*}}{2 L_{r}}\right)^{2}+\frac{R_{s} T_{o p t}}{1.5 n_{p} L_{r}}$

If only the stator reactive current is optimized, system losses $\left(P_{c}\right)$ are given by

$P_{c}=R_{s}\left(\frac{T_{o p t}}{1.5 n_{p} \psi_{r}^{*}}-\frac{\psi_{r}^{*}}{2 L_{r}}\right)^{2}+\frac{R_{s} T_{o p t}}{1.5 n_{p} L_{r}}$

The output power of the wind turbine and the gearbox is equal to $T_{o p t} \omega_{o p t}$ when the DFIG operates at its MPP. In order to clearly illustrate the difference in system losses and efficiency between optimized and non-optimized operation, the decreased system losses ratio $\left(\Delta \eta_{f c}\right.$ and $\left.\Delta \eta_{c}\right)$ and increased system efficiency $\left(\Delta \xi_{f c}\right.$ and $\left.\Delta \xi_{c}\right)$ are defined by

$$
\left\{\begin{array}{l}
\Delta \eta_{f c}=\frac{P_{u}-P_{f c}}{P_{u}} \\
\Delta \eta_{c}=\frac{P_{u}-P_{c}}{P_{u}} \\
\Delta \xi_{f c}=\frac{P_{u}-P_{f c}}{T_{o p t} \omega_{o p t}} \\
\Delta \xi_{c}=\frac{P_{u}-P_{c}}{T_{o p t} \omega_{o p t}}
\end{array}\right.
$$

The parameters of wind power generation system are listed in Table 1. Based on (18)-(24), the curves of rotor flux, stator current, system losses, decreased system losses, and increased system efficiency are shown in Figs. 3 and 4. As the synchronous speed $\left(n_{s y n}\right)$ is $1500 \mathrm{rpm}, \Delta \eta_{f c}$ and $\Delta \eta_{c}$ increase from $25 \%$ to $82 \%$, and from $25 \%$ to $50 \%$ when the rotor speed ranges from $1.2 n_{s y n}$ to $0.4 n_{s y n}$, and $\Delta \xi_{f c}$ and $\Delta \xi_{c}$ increase from $1 \%$ to $19 \%$, and from $1 \%$ to $12 \%$. In [19], the improvement in efficiency varies from $0 \%$ to $12 \%$ when rotor speed $n_{r}$ decreases from $1.2 n_{s y n}$ to $0.4 n_{s y n}$ at low torque and rotor speed level. 
Table 1 Parameters for the DFIG generation system

\begin{tabular}{lll}
\hline Symbol & Quantity & Value \\
\hline$R_{s}$ & stator resistance & $0.88 \Omega$ \\
$L_{l s}$ & Stator leakage reactance & $5.6 \mathrm{mH}$ \\
$R_{r}$ & Rotor resistance & $0.88 \Omega$ \\
$L_{l r}$ & Rotor leakage reactance & $5.6 \mathrm{mH}$ \\
$L_{m}$ & Mutual inductance & $87.5 \mathrm{mH}$ \\
$n_{p}$ & Pair of poles & 2 \\
$J$ & Moment of inertia & $0.015 \mathrm{~kg} \mathrm{~m}$ \\
$n_{s y n}$ & Synchronous speed & $1500 \mathrm{r} / \mathrm{min}^{2}$ \\
$n_{r}$ & Rated rotor speed & $1680 \mathrm{rpm}$ \\
$f_{1}$ & Rated stator frequency & $50 \mathrm{~Hz}$ \\
$V_{s}$ & Rated phase stator voltage & $311 \mathrm{~V}$ \\
$U_{d c}$ & DC voltage & $650 \mathrm{~V}$ \\
\hline
\end{tabular}

Therefore, the proposed optimization method achieves better performance especially at low and moderate rotor speeds. Systems losses are reduced and system efficiency is improved.

The feasibility of operating a DFIG at low wind speed is validated with fixed slip in [14]. Hence, we focus on the coordinated MPC scheme using rotor flux and stator current predictive method to track the optimized control targets and improve the performance of the DFIG within the normal rotor speed range from 1.05 to $1.68 \mathrm{krpm}$ in the following simulation and experiment.

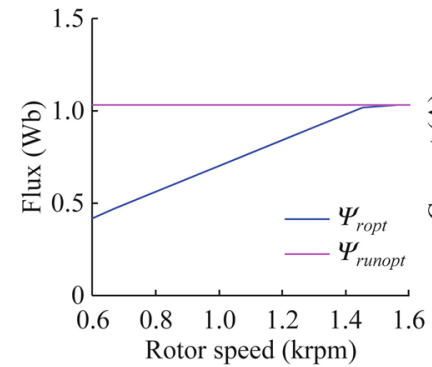

(a) Rotor flux

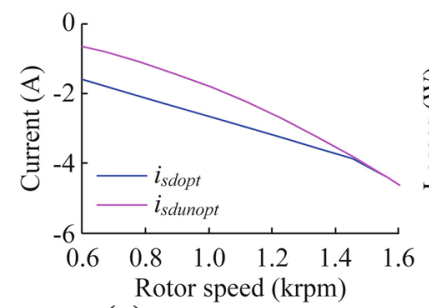

(c) Stator active current

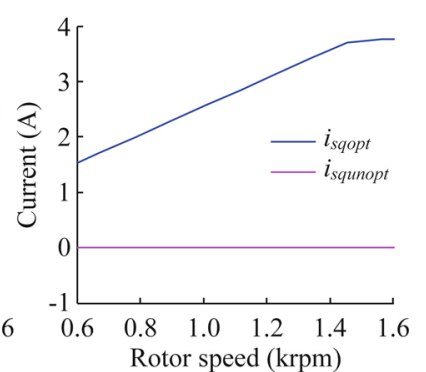

(b) Stator reactive current

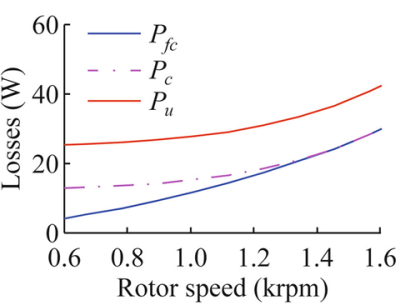

(d) System losses
Fig. 3 Variations of losses, flux and current with rotor speed

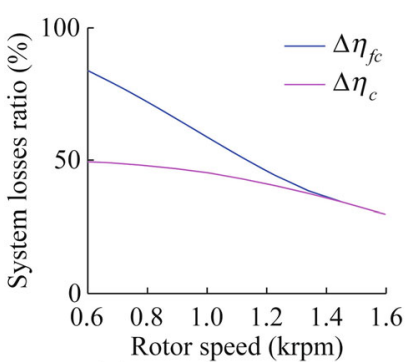

(a) Decreased losses ratio

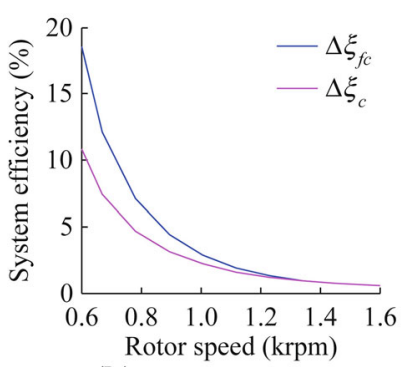

(b) Increased efficiency
Fig. 4 Decreased system losses and increased system efficiency

\subsection{Predictive model of DFIG}

From (2) and (3), the state equation of DFIG can be derived in the form

$\frac{\mathrm{d} \boldsymbol{x}}{\mathrm{d} t}=\boldsymbol{A x}+\boldsymbol{B u}$

where

$\boldsymbol{x}=\left[\begin{array}{llll}\psi_{r d} & \psi_{r q} & i_{s d} & i_{s q}\end{array}\right]^{\mathrm{T}}, \quad \boldsymbol{u}=\left[\begin{array}{llll}u_{r d} & u_{r q} & u_{s d} & u_{s q}\end{array}\right]^{\mathrm{T}}$,

$\boldsymbol{A}=\left[\begin{array}{cccc}\frac{-R_{r}}{L_{r}} & \omega_{s} & \beta R_{r} & 0 \\ \omega_{s} & \frac{-R_{r}}{L_{r}} & 0 & \beta R_{r} \\ \frac{\beta R_{r}}{\alpha L_{r}} & \frac{\beta \omega_{r}}{\alpha} & \frac{R_{s}+\beta^{2} R_{r}}{\alpha} & \omega_{1} \\ \frac{-\beta \omega_{r}}{\alpha} & \frac{\beta R_{r}}{\alpha L_{r}} & \omega_{1} & \frac{-R_{s}+\beta^{2} R_{r}}{\alpha}\end{array}\right]$,

$\boldsymbol{B}=\left[\begin{array}{cccc}1 & 0 & 0 & 0 \\ 0 & 1 & 0 & 0 \\ -\beta / \alpha & 0 & 1 & 0 \\ 0 & -\beta / \alpha & 0 & 0\end{array}\right], \quad\left\{\begin{array}{l}\alpha=\frac{L_{r} L_{s}-L_{m}^{2}}{L_{r}} \\ \beta=\frac{L_{m}}{L_{r}}\end{array}\right.$

Stator current and rotor flux are the system state variables, and stator and rotor voltages are the system inputs for the RSC and the SSC respectively. The coefficient matrix $\boldsymbol{A}$ varies with rotor angular frequency. Rotor voltage is regulated by the RSC to confine rotor flux to its rated value with a coupled term including the stator current. Stator voltage is regulated by SSC to confine stator current to its reference with a coupled term including the rotor flux. The stator current and the rotor flux are therefore coupled strongly together. Separate controllers for the RSC and the SSC would generate system errors. Meanwhile it is difficult to decouple and ensure system stability over its full operational range using simple PI controllers. Therefore, coordinated MPC controllers for the RSC and the SSC are proposed to make the DFIG operate at its MPP and to improve its steady-state and transient performance, using a rotor flux and stator current predictive method without decoupling. The rotor flux is estimated from rotor 
and stator currents according to (3) [32]. Stator, rotor, and mutual inductances $\left(L_{s}, L_{r}, L_{m}\right)$, are evaluated off-line.

The forward-difference Euler formula is adopted as the numerical approximation to predict the derivative for the next sample time:

$\frac{\mathrm{d} \boldsymbol{x}}{\mathrm{d} t}=\frac{\Delta \boldsymbol{x}(k)}{\Delta t} \approx \frac{\boldsymbol{x}(k+1)-\boldsymbol{x}(k)}{T}$

where $\boldsymbol{x}$ is a state variable; $T$ is the sampling period and $k$ is the time stamp. The discrete predictive model for the DFIG is therefore given by

$\boldsymbol{x}(k+1)=(\boldsymbol{A}(k) T+\boldsymbol{I}) \boldsymbol{x}(k)+\boldsymbol{B} T \boldsymbol{u}(k)$

\subsection{Delay compensation}

Current sampling and rotor flux calculation cannot occur simultaneously, and the sampled currents differ from the actual values at the time of calculation. These errors can be significant if the delay time is substantial. It is necessary to predict the stator current and the rotor flux for the sample time, to match the derivative prediction. They are estimated for sample time $k$ by the previous values and expressed as

$\boldsymbol{x}(k)=(\boldsymbol{A}(k-1) T+\boldsymbol{I}) \boldsymbol{x}(k-1)+\boldsymbol{B} T \boldsymbol{u}(k-1)$

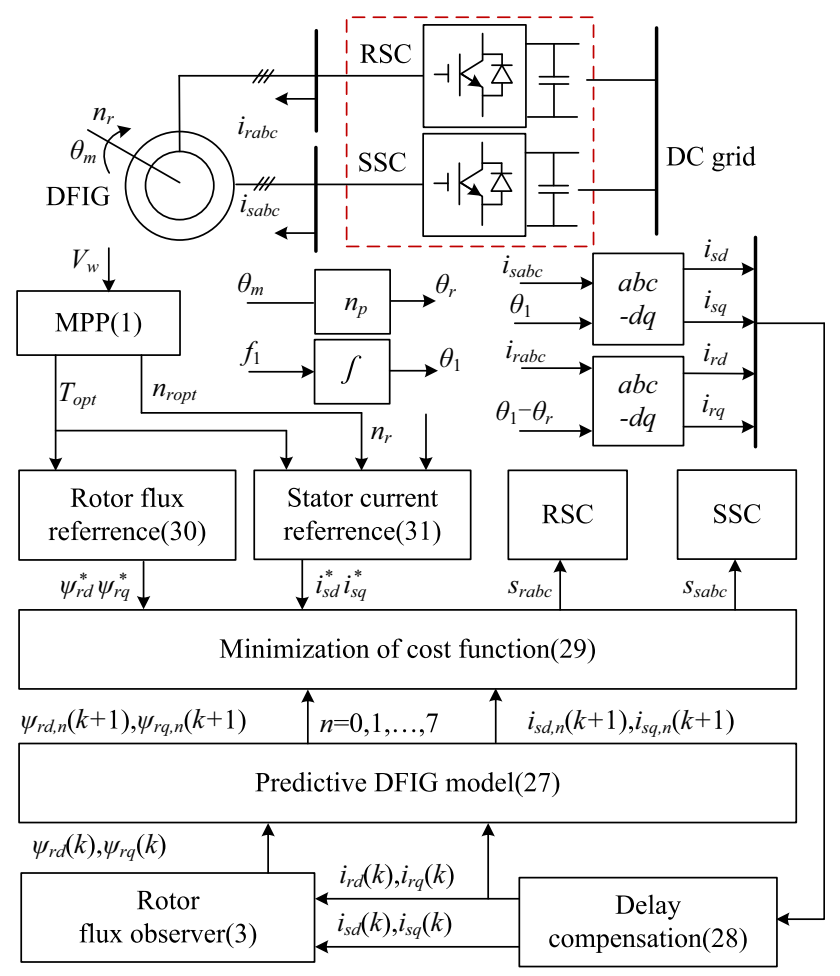

Fig. 5 Control scheme for the RSC and the SSC

\subsection{Cost function}

A cost function is the evaluation criterion to determine the optimum switching state for the next sample time and output the optimum vector with the least error. The stator current and rotor flux predictive method is used to keep the rotor flux stable and to track the stator current reference. Rotor flux and stator current targets are easily achieved by penalizing switching states that produce predictions distant from reference value. Thus the cost functions for the SSC and the RSC are defined as

$\left\{\begin{array}{l}g_{s s C}=k_{1}\left|i_{s d}^{*}-i_{s d}^{p}\right|+k_{2}\left|i_{s q}^{*}-i_{s q}^{p}\right| \\ g_{R S C}=k_{3}\left|\psi_{r d}^{*}-\psi_{r d}^{p}\right|+k_{4}\left|\psi_{r q}^{*}-\psi_{r q}^{p}\right|\end{array}\right.$

where $k_{1}, k_{2}, k_{3}$, and $k_{4}$ are the weight coefficients that influence relative performance against each of the control targets. In this paper, $k_{1}, k_{2}, k_{3}$, and $k_{4}$ are chosen as 1 . Target values are denoted by the superscript “*”, and the predicted values from (27) are denoted by the superscript " $p$ ". The rotor flux reference values are obtained from (6) as

$\left\{\begin{array}{l}\psi_{r d}^{*}=0 \\ \psi_{r q}^{*}=\psi_{r}\end{array}\right.$

The stator current reference values are given from (4)(6) and (20) as

$\left\{\begin{array}{l}i_{s d}^{*}=\frac{T_{o p t}-k_{p}\left(n_{o p t}-n_{r}\right)}{1.5 n_{p} \beta \psi_{r}} \\ i_{s q}^{*}=\frac{\psi_{r}}{2 L_{r}}\end{array}\right.$

\subsection{Coordinated and optimized control scheme}

From the above analysis, the whole control scheme is shown in Fig. 5. The MPP model estimates the optimal speed and torque ( $\left.n_{\text {ropt }}, T_{\text {opt }}\right)$ using (1) according to the wind speed $\left(V_{w}\right)$. The rotor flux and stator current reference values $\left(\psi_{r d}^{*}, \psi_{r q}^{*}, i_{s d}^{*}, i_{s q}^{*}\right)$ come from (30) and (31) with the inputs of $T_{o p t}, n_{\text {ropt }}$, and $n_{r}$. The rotor speed, and stator and rotor currents $\left(n_{r}, i_{s a b c}, i_{r a b c}\right)$ are measured and transformed into their $d q$ components $\left(i_{s d}, i_{s q}, i_{r d}, i_{r q}\right)$ in the synchronous frame. The rotor and stator currents $\left(i_{s d}(k), i_{s q}(k), i_{r d}(k), i_{r q}(k)\right)$ for sample time $k$ come from the delay compensation model illustrated by (28). The rotor fluxes $\left(\psi_{r d}(k), \psi_{r q}(k)\right)$ for sample time $k$ are estimated from the rotor and stator currents using (3). The predictive DFIG model in (27) is used to output the predicted rotor fluxes and stator currents $\left(\psi_{r d}(k+1), \psi_{r d}\right.$ $\left.(k+1), i_{s d}(k+1), i_{s q}(k+1)\right)$ for sample time $k+1$. Cost functions given by (29) determine the optimum switching state during the next sampling period, which 
allows the optimum voltage vectors $\left(s_{r a b c}, s_{s a b c}\right)$ of the RSC and the SSC to be calculated using the inputs of predicted rotor fluxes and stator currents.

\section{Simulations}

The DFIG system parameters in the following simulation and experiment are listed in Table 1.

Changes in rotor speed are modeled in a simulation platform to verify the feasibility of the proposed control scheme. During the first stage, $n_{\text {ropt }}$ is set to $1680 \mathrm{rpm}$ which is assumed to be the rated rotor speed of the DFIG. Then at $0.3 \mathrm{~s}$ the rotor starts declining quickly during the transient stage, reaching $1050 \mathrm{rpm}$ at $0.45 \mathrm{~s}$, where it remains in the low-speed stage for the rest of the simulation. Simulation results are shown in Figs. 6, 7 and 8.

\subsection{Steady-state performance analysis}

The rotor flux and stator current are stable and track their reference values closely before $0.3 \mathrm{~s}$ when DFIG operates at its rated rotor speed. $n_{r}$ is confined to its reference value, indicating that the DFIG operates at its MPP. The rotor flux amplitude remains stable at $1.03 \mathrm{~Wb}$ with a frequency of $6 \mathrm{~Hz}$. The stator current $\left(I_{s}\right)$ is a sine wave with amplitude of $6.3 \mathrm{~A}$ and frequency of $50 \mathrm{~Hz}$. The stator reactive current is $3.77 \mathrm{~A}$ and, together with rotor reactive current, ensures the rotor flux stable. The filtered stator voltage amplitude is confined to $311 \mathrm{~V}$. A phase difference exists between the stator current and the voltage.

At the rotor speed of $1050 \mathrm{rpm}$, the stator current amplitude is $3.87 \mathrm{~A}$ with its active and reactive current confined to their reference values of -2.79 and $2.68 \mathrm{~A}$ after $0.5 \mathrm{~s}$, which accords with (31) and Fig. 3. The RSC confines the rotor flux to $0.732 \mathrm{~Wb}$, which varies with $T_{\text {opt }}$ and accords with (19) and Fig. 3. The stator voltage amplitude declines to $227 \mathrm{~V}$ due to decreased rotor flux.

Thus, the MPC controllers make the DFIG operate steadily and track the optimized targets effectively.

\subsection{Transient performance analysis}

The transient performance is analyzed when rotor speed declines rapidly from $0.3 \mathrm{~s}$ in Fig. 6. Owing to the generator inertia and control delay, $n_{r}$ reaches its reference value at $0.45 \mathrm{~s}$. With the stator active current reference increasing and rotor flux reference decreasing from 0.3 to $0.38 \mathrm{~s}, T_{e}$ maintains its maximum value of $15 \mathrm{~N} \cdot \mathrm{m}$ to make $n_{r}$ fall quickly, and then reduces to its reference value, which accords with the expected behaviour of the MPP controller

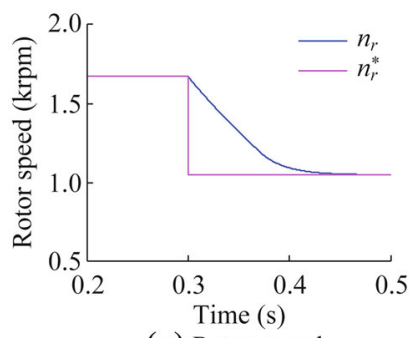

(a) Rotor speed

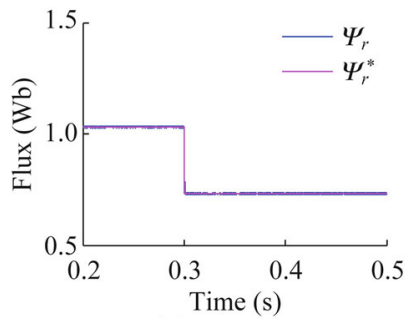

(c) Rotor flux

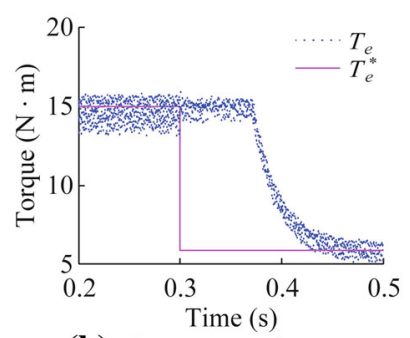

(b) Electromagnetic torque

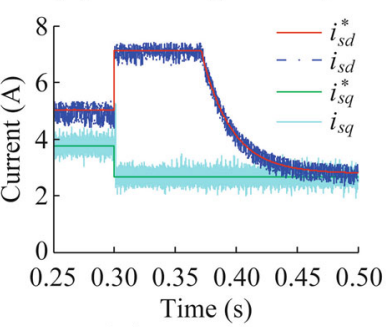

(d) Stator current
Fig. 6 Rotor speed, flux, current, and torque variations during the transient stage of the simulation

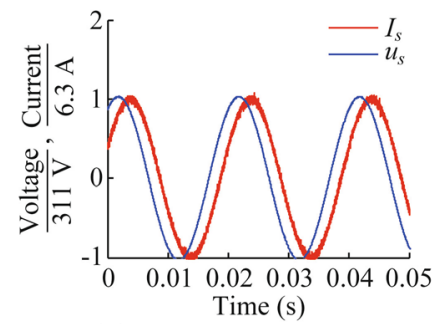

(a) Stator voltage and current

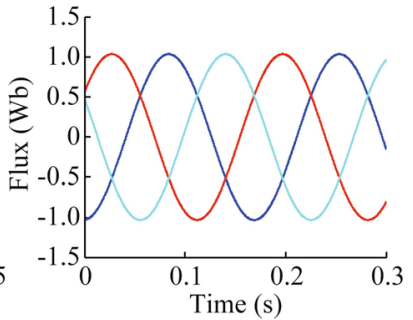

(b) Rotor flux
Fig. 7 Rotor flux and stator current during the rated-speed stage of the simulation

(5). The rotor flux and stator current closely follow their references values.

Thus, the transient performance of the DFIG is excellent when wind speed falls sharply, and all control targets are met smoothly and quickly.

\section{Experiments}

\subsection{Test bench overview}

A laboratory-scale experimental test bench was designed to verify the proposed control scheme. It consists of a DFIG, RSC, SSC, induction motor (IM), IM driver, and battery storage. Its schematic diagram and photograph are shown in Fig. 9 and Fig. A1 (as shown in the Appendix A) respectively. The IM is used to emulate a wind turbine, and its speed is controlled by the IM driver. Battery storage is connected with the stator and rotor, by the RSC and SSC respectively, to keep the DC bus voltage stable. Two $\mathrm{d} u / \mathrm{d} t$ filter inductors are 


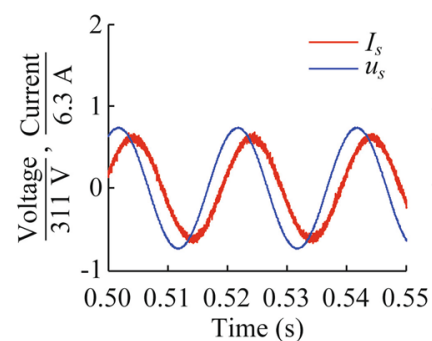

(a) Stator voltage and current

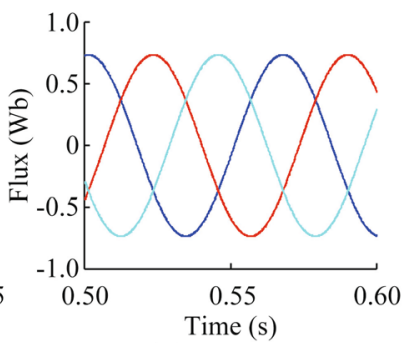

(b) Rotor flux

Fig. 8 Rotor flux and stator current during the low-speed stage with a rotor speed of $1050 \mathrm{rpm}$

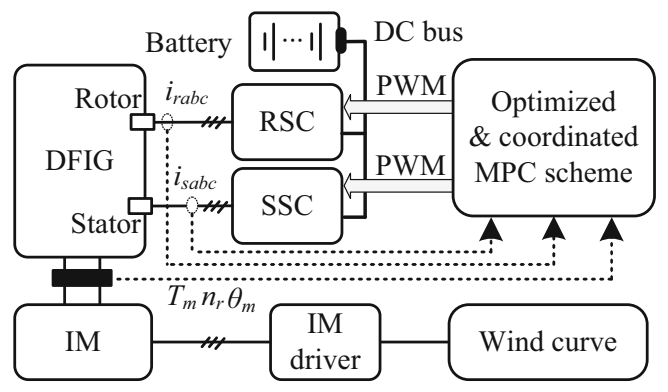

Fig. 9 Schematic diagram of the test bench

added to the rotor and stator sides to protect the DFIG from sharp voltage changes. An incremental encoder and a torque sensor are used to measure the rotor position, speed, and torque. The proposed control scheme is implemented in a DSP28335 processing board with a switching frequency of $10 \mathrm{kHz}$. The stator voltage amplitude is obtained by the signal processing circuit to observe its variation directly.

\subsection{Experimental results in normal speed range}

A quasi-constant rotor speed ramping up from 1050 to $1680 \mathrm{rpm}$ over $3 \mathrm{~s}$ was achieved using the induction motor. Rotor flux and stator current reference curves are presented in Fig. 3. An experimental comparison is made between the two control schemes with optimized and non-optimized targets, shown in Figs. 10-11.

In both figures $n_{r}$ increases from 1050 to $1680 \mathrm{rpm}$ and follows its reference curve closely. $T_{m}$ ranges from 5.9 to $15 \mathrm{~N} \cdot \mathrm{m}$ and has the same trend as $n_{r}$. This is consistent with the DFIG operating at its MPP in the two cases. The peak amplitude of the induced stator voltage, allowing for the effect of the low-pass filter, ramps from 227 to $311 \mathrm{~V}$, which conforms to (12).

The stator current follows its reference value closely at rotor speeds of 1680 and 1050 rpm in Figs. 10 and 11. The peak stator current amplitude varies from 3.87 to $6.3 \mathrm{~A}$ in Fig. 10, and from 2.02 to $5.05 \mathrm{~A}$ in Fig. 11. The rotor peak current amplitude varies from 3.83 to $6.4 \mathrm{~A}$ and from 7.8 to

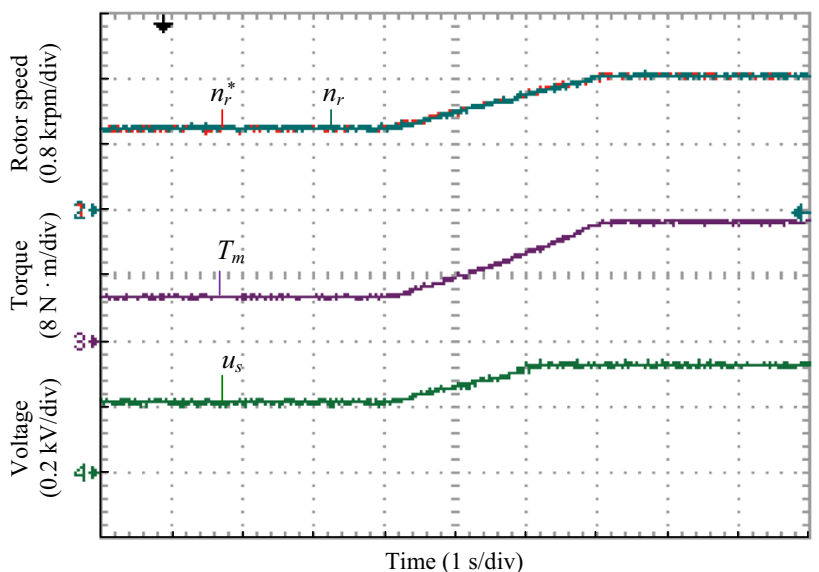

(a) Variations of rotor speed, torque and voltage

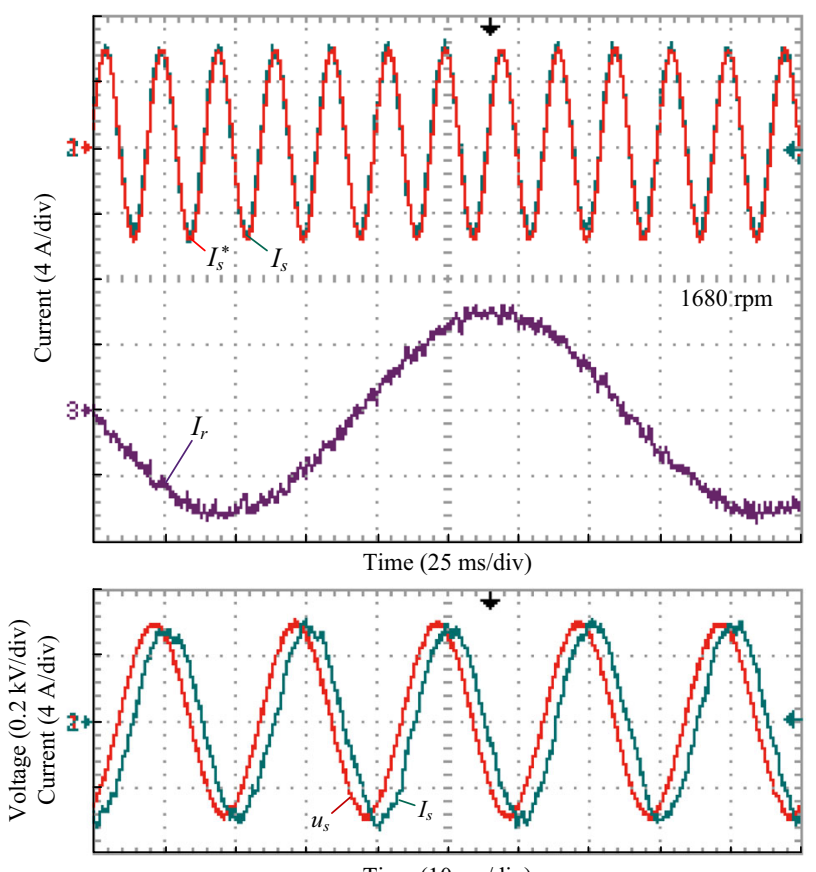

(b) Variations of current and voltage at the rated rotor speed

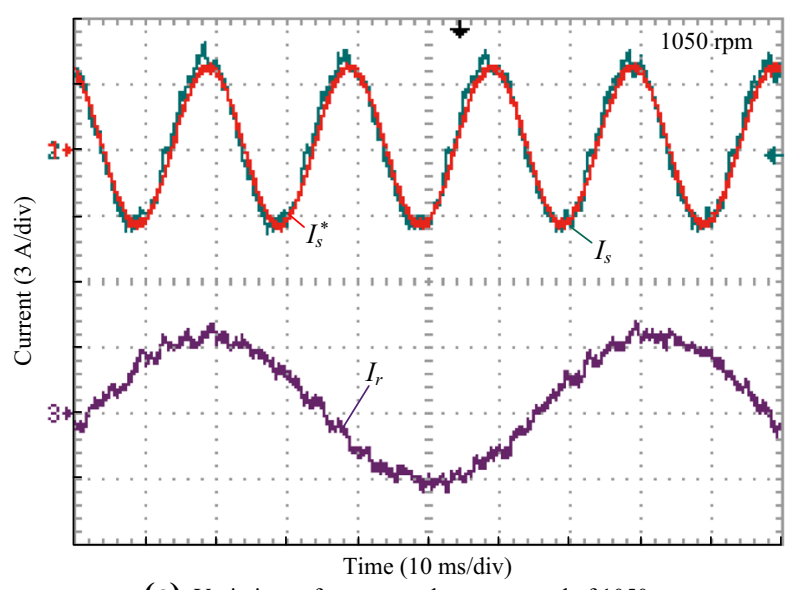

(c) Variations of current at the rotor speed of $1050 \mathrm{rpm}$

Fig. 10 Experiment results for the optimization control scheme 


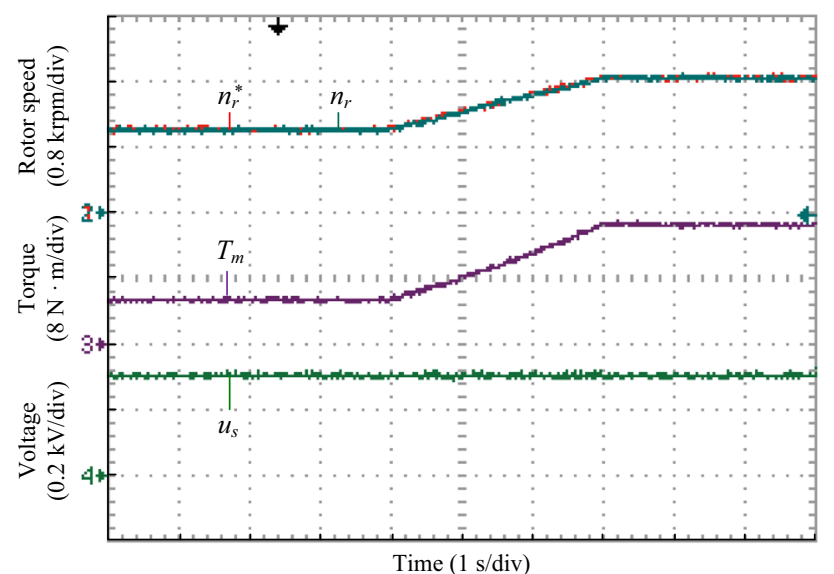

(a) Variations of rotor speed, torque and voltage

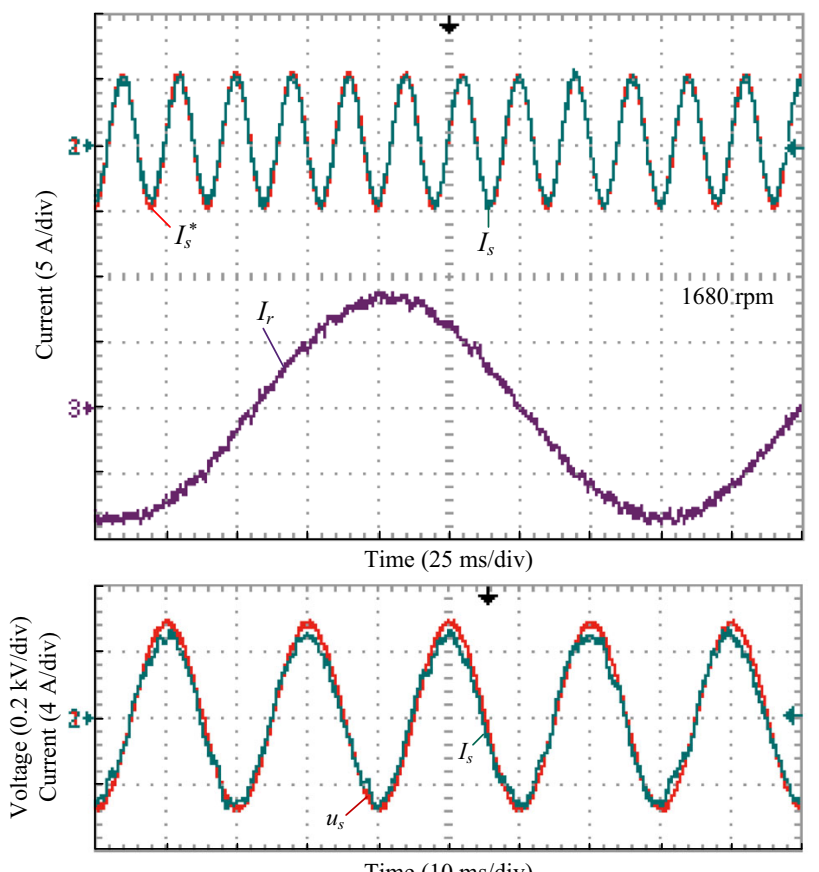

(b) Variations of current and voltage at the rated rotor speed

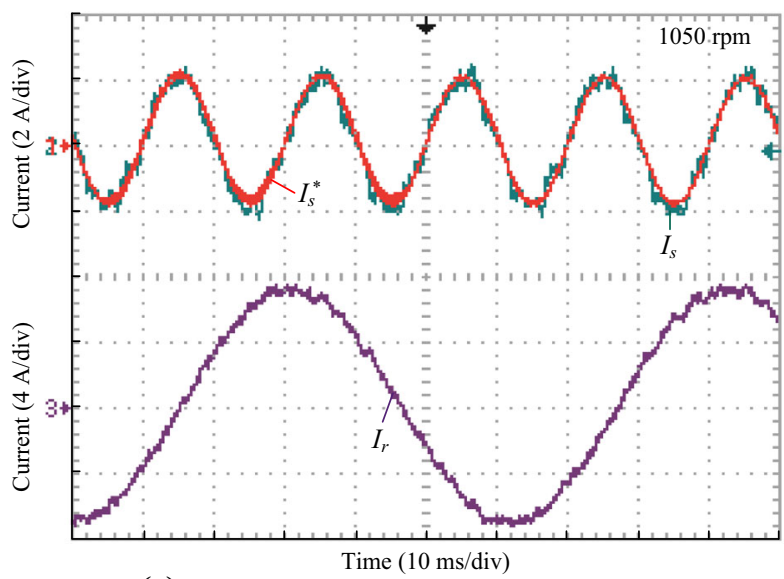

(c) Variations of current at the rotor speed of $1050 \mathrm{rpm}$

Fig. 11 Experiment results for non-optimization control scheme

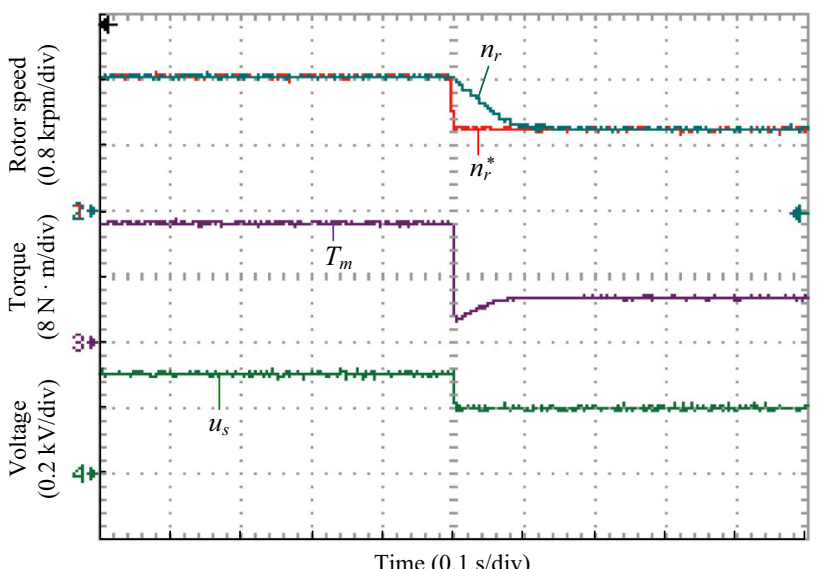

(a) Variations of rotor speed, torque and voltage

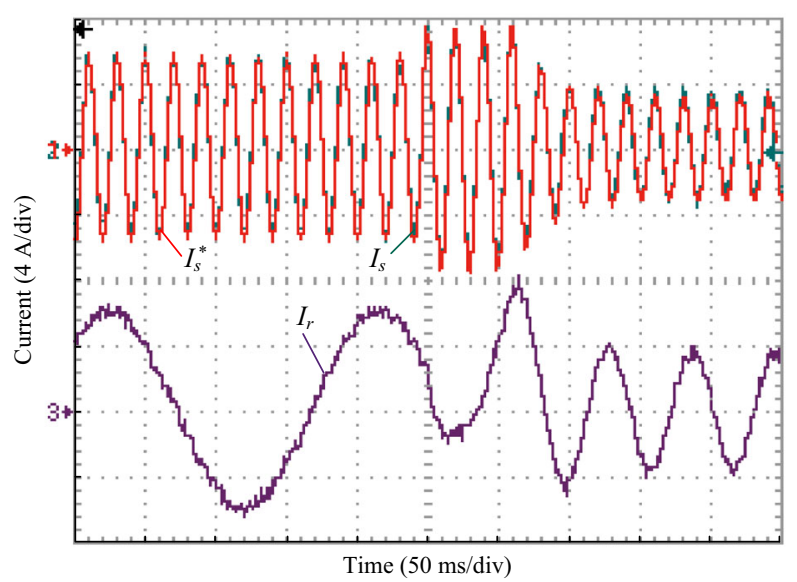

(b) Variations of stator and rotor currents

Fig. 12 Experiment results in abrupt speed case

9 A respectively in the two cases. The optimized stator current supports the rotor flux using more reactive current than the non-optimized one. The optimized rotor current supports less reactive current than the non-optimized one. The rotor excitation frequency varies from 15 to $6 \mathrm{~Hz}$ in both cases.

The stator voltage in Fig. 10 has a different phase to the stator current which compensates reactive current according to (20). The stator voltage and current have the same phase in Fig. 11, and stator reactive current is zero. At the rated rotor speed, the losses of the DFIG between two cases are basically equal. Therefore, the losses of the DFIG are analyzed at the rotor speed of $1050 \mathrm{rpm}\left(n_{r}=0.7 n_{s y n}\right)$. The measured input power at low rotor speed is $648 \mathrm{~W}$, and the output powers for the optimized and non-optimized cases are 628 and $610 \mathrm{~W}$ respectively. So we could get the increased system efficiency about $2.7 \%$ by (24), which accords with the result in Fig. 4b.

In addition, compared with the current and torque curves in [6], the curves in Fig. 10 have less harmonic contents and fewer steady-state errors, and are more smooth. 
Thus, it could be concluded that the control scheme with optimized control targets can make DFIG operate steadily at its MPP over the whole operational speed range, and improve the system efficiency.

\subsection{Experiment results during abrupt rotor speed variation}

To validate the transient performance of the DFIG during an abrupt rotor speed variation, the rotor speed was changed sharply from 1680 to $1050 \mathrm{rpm}$ in less than $0.1 \mathrm{~s}$. The results are shown in Fig. 12.

$n_{r}$ reaches its reference value smoothly after $0.1 \mathrm{~s}$, and $T_{m}$ varies from 15 to $5.9 \mathrm{~N} \cdot \mathrm{m}$ quickly with a small overshoot. The stator current tracks its reference value smoothly and quickly without overcurrent. The rotor current changes very quickly. The experiment results therefore accord with the simulated behavour shown in Fig. 6 . Compared with the current and torque curves in [6], the curves in Figs. 11-12 have less overshoot and quicker dynamic response.

Thus, the coordinated MPC controllers improve the transient performance of DFIG when the rotor speed drops down sharply.

\section{Conclusion}

Based on the results and analysis, the following conclusions may be drawn:

1) The optimized control targets are analytically obtained and validated on the detailed model of system losses. And its parameters come from a practical DFIG system.

2) The optimized control targets effectively increase the system efficiency from $1 \%$ to $19 \%$ when rotor speed decreases from $1.2 n_{s y n}$ to $0.4 n_{s y n}$, and minimize the system losses of a DFIG. The lower of the rotor speed is, the higher the increased system efficiency is.

3) The coordinated MPC controllers effectively track the optimized control targets to make DFIG operate at its MPP model, and improve the system efficiency about $2.7 \%$ at the rotor speed of $0.7 n_{s y n}$ in the experiment.

4) The coordinated MPC controllers make all control targets track their references within $0.15 \mathrm{~s}$ and without impulse when rotor speed drops down sharply in experiment. The transient performance of DFIG is improved.

In further study, this experiment will be extended to verify the effectiveness of the proposed control scheme over the full rotor speed range.
Acknowledgements This work was supported by National Natural Science Foundation of China (No. 61473170) and Key R\&D Plan Project of Shandong Province, PRC (No. 2016GSF115018).

Open Access This article is distributed under the terms of the Creative Commons Attribution 4.0 International License (http:// creativecommons.org/licenses/by/4.0/), which permits unrestricted use, distribution, and reproduction in any medium, provided you give appropriate credit to the original author(s) and the source, provide a link to the Creative Commons license, and indicate if changes were made.

\section{Appendix A}

See Fig. A1.

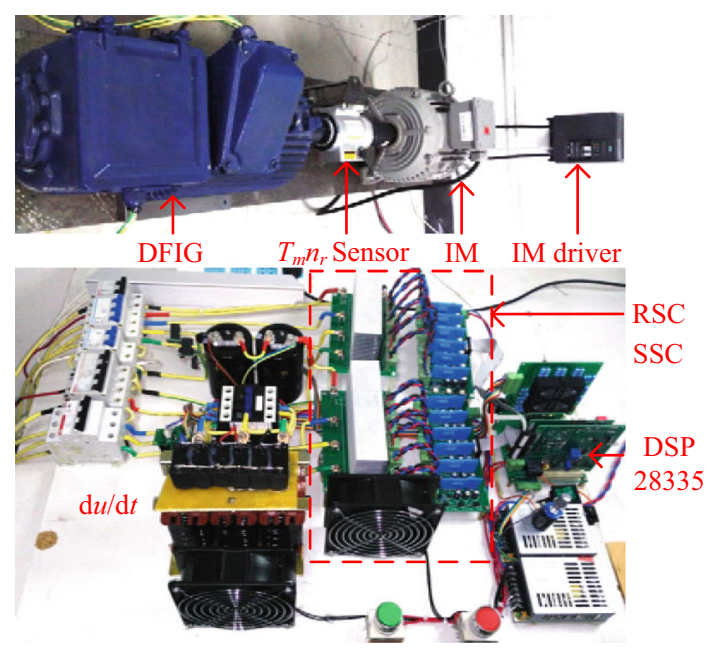

Fig. A1 Photograph of the test bench

\section{References}

[1] Cheng M, Zhu Y (2014) The state of the art of wind energy conversion systems and technologies: a review. Energy Convers Manage 88:332-347

[2] Zou J, Peng C, Xu H et al (2015) A fuzzy clustering algorithmbased dynamic equivalent modeling method for wind farm with DFIG. IEEE Trans Energy Convers 30(4):1329-1337

[3] Zhao J, Lyu X, Fu Y et al (2016) Coordinated microgrid frequency regulation based on DFIG variable coefficient using virtual inertia and primary frequency control. IEEE Trans Energy Convers 31(3):833-845

[4] Phan VT, Nguyen DT, Trinh QN et al (2016) Harmonics rejection in stand-alone doubly-fed induction generators with nonlinear loads. IEEE Trans Energy Convers 31(2):815-817

[5] Chen W, Huang AQ, Li C et al (2013) Analysis and comparison of medium voltage high power DC/DC converters for offshore wind energy systems. IEEE Trans Power Electron 28(4):20142023

[6] Iacchetti MF, Marques GD, Perini R (2015) A scheme for the power control in a DFIG connected to a dc bus via a diode rectifier. IEEE Trans Power Electron 30(3):1286-1296 
[7] Marques GD, Iacchetti MF (2014) Inner control method and frequency regulation of a DFIG connected to a dc link. IEEE Trans Energy Convers 29(2):435-444

[8] Iacchetti MF, Marques GD, Perini R (2015) Torque ripple reduction in a DFIG-DC system by resonant current controllers. IEEE Trans Power Electron 30(8):4244-4254

[9] Iacchetti MF, Marques GD, Perini R (2014) Operation and design issues of a doubly fed induction generator stator connected to a dc net by a diode rectifier. IET Elect Power Appl 8(8):310-319

[10] Marques GD, Iacchetti MF (2015) A self-sensing stator-currentbased control system of a DFIG connected to a dc-link. IEEE Trans Ind Electron 62(10):6140-6150

[11] Marques GD, Iacchetti MF (2014) Stator frequency regulation in a field-oriented controlled DFIG connected to a dc link. IEEE Trans Ind Electron 61(11):5930-5939

[12] Yu N, Nian H, Quan Y (2011) A novel dc grid connected DFIG system with active power filter based on predictive current control. In: Proceedings of international conference on electrical machines and systems, Beijing, China, 20-23 Aug 2011, pp 1-5

[13] Zhu R, Chen Z, Wu X (2015) Diode rectifier bridge-based structure for DFIG-based wind turbine. In: Proceedings of IEEE applied power electronics conference and exposition, Charlotte, North Carolina, USA, 15-19 Mar 2015, pp 1290-1295

[14] Nian H, Yi X (2015) Coordinated control strategy for doubly-fed induction generator with dc connection topology. IET Renew Power Gener 9(7):747-756

[15] Yan S, Zhang A, Zhang $\mathrm{H}$ et al (2014) A novel converter system for DFIG based on dc transmission. In: Proceedings of 40th annual conference of the IEEE industrial electronics society, Dallas, TX, USA, 29 Oct-01 Nov 2014, pp 4133-4139

[16] Nguyen Tien H, Scherer CW, Scherpen JMA et al (2016) Linear parameter varying control of doubly fed induction machines. IEEE Trans Ind Electron 63(1):216-224

[17] Lorenz RD, Yang SM (1992) Efficiency-optimized flux trajectories for closed-cycle operation of field-orientation induction machine drives. IEEE Trans Ind Appl 28(3):574-580

[18] Preindl M, Bolognani S (2015) Optimal state reference computation with constrained MTPA criterion for PM motor drives. IEEE Trans Power Electron 30(8):4524-4535

[19] Marques GD, Iacchetti MF (2016) Field-weakening control for efficiency optimization in a DFIG connected to a dc-link. IEEE Trans Ind Electron 63(6):3409-3419

[20] Tremblay E, Atayde S, Chandra A (2011) Comparative study of control strategies for the doubly fed induction generator in wind energy conversion systems: a DSP-based implementation approach. IEEE Trans Sustain Energy 2(3):288-299

[21] Cardenas R, Pena R, Alepuz S et al (2013) Overview of control systems for the operation of DFIGs in wind energy applications. IEEE Trans Ind Electron 60(7):2776-2798

[22] Nian H, Cheng P, Zhu Z (2015) Direct power control of doubly fed induction generator without phase-locked loop in synchronous reference frame during frequency variations. IET Renew Power Gener 9(6):576-586

[23] Zhang Y, Li Z, Zhang Y et al (2013) Performance improvement of direct power control of PWM rectifier with simple calculation. IEEE Trans Power Electron 28(7):3428-3437

[24] Rodriguez J, Kazmierkowski MP, Espinoza JR et al (2013) State of the art of finite control set model predictive control in power electronics. IEEE Trans Ind Informat 9(2):1003-1016

[25] Cortes P, Rodriguez J, Silva C et al (2012) Delay compensation in model predictive current control of a three-phase inverter. IEEE Trans Ind Electron 59(2):1323-1325
[26] Lim CS, Levi E, Jones M et al (2014) FCS-MPC-based current control of a five-phase induction motor and its comparison with PI-PWM control. IEEE Trans Ind Electron 61(1):149-163

[27] Kou P, Liang D, Gao F et al (2015) Coordinated predictive control of DFIG-based wind-battery hybrid systems: using nongaussian wind power predictive distributions. IEEE Trans Energy Convers 30(2):681-695

[28] Xu L, Zhi D, Williams BW (2009) Predictive current control of doubly fed induction generators. IEEE Trans Ind Electron 56(10):4143-4153

[29] Yang H, Zhang Y, Walker PD et al (2017) A method to start rotating induction motor based on speed sensorless model predictive control. IEEE Trans Energy Convers 32(1):359-368

[30] Bayhan S, Abu-Rub H, Ellabban O (2016) Sensorless model predictive control scheme of wind-driven doubly fed induction generator in dc microgrid. IET Renew Power Gener 10(4):514-521

[31] Miller NW, Sanchez-Gasca JJ, Price WW et al (2003) Dynamic modeling of GE 1.5 and 3.6 MW wind turbine-generators for stability simulations. In: Proceedings of IEEE power engineering society general meeting, Toronto, Ont, Canada 13-17 Jul 2003, pp 1977-1983.

[32] Abad G, Lopez J, Rodriguez M et al (2011) Doubly fed induction machine: modeling and control for wind energy generation. Wiley, Hoboken

Shaomin YAN received B.S. in Mechanical and Electrical Engineering from Qilu University of Technology in 2001 and M.S. in Electrical and Electronic Engineering from Zhejiang University of Technology in 2004. From 2004 to 2012, he was a Lecturer in the Electrical Engineering School, Qufu Normal University. $\mathrm{He}$ is currently working towards the Ph.D. degree in Electrical Engineering School, Xi'an Jiaotong University. His current research interests include wind energy conversion system and power electronics.

Aimin ZHANG received the B.S., M.S. and Ph.D. degrees in Electrical Engineering from Xi' an Jiaotong University in 1983, 1985 and 2008 respectively. She is currently a Professor in the Electronic and Information Engineering School, Xi' an Jiaotong University. Her current research interests include FACTS, non-linear control theory, and power electronics.

Hang ZHANG received the B.S. and M.S. degrees in Electrical Engineering from Xi'an Jiaotong University in 1983 and 1985 respectively. He is currently an Assistant Professor in the Electrical Engineering School, Xi' an Jiaotong University. His current research interests include HVDC transmission system and power electronics.

Jianhua WANG received the B.S., M.S. and Ph.D. degrees in Electrical Engineering from Xi' an Jiaotong University in 1979, 1983, and 1985 respectively. He is currently a Professor in the Electrical Engineering School, Xi' an Jiaotong University. His current research interests include intelligent apparatus technique, intelligent $\mathrm{HV}$ switchgear, and power electronics.

Bin CAI received $\mathrm{Ph} . \mathrm{D}$. degrees in Electrical Engineering from Xi' an Jiaotong University in 2004. He is currently a Professor in the Engineering School, Qufu Normal University. His current research interests include wind energy conversion system and power electronics. 